Makale Gönderim Tarihi:01.12.2014～Makale Kabûl Tarihi:27.03.2015

\title{
Pedagojik Formasyon Eğitimi Sertifika Programı Öğrencilerinin Karakter Eğitimine İlişkin Görüşleri
}

\author{
Yrd. Doç. Dr. Salih USLU \\ Niğde Üniversitesi, Eğitim Fakültesi, İlköğretim Bölümü Sosyal Bilgiler Eğitimi \\ Ana Bilim Dalı, Merkez Yerleşke, Niğde / Türkiye
}

\section{$\ddot{O} z$}

$\mathrm{Bu}$ çalışmanın amacı, pedagojik formasyon eğitimi sertifika programı öğrencilerinin karakter eğitimine ilişkin görüşlerinin çeşitli değişkenlere göre incelenmesidir. Araştırma verileri, 2013-2014 Eğitim-Öğretim Yllı’nda bir devlet üniversitesinin pedagojik formasyon eğitimi sertifika programına kayıtlı 235 öğrenciden elde edilmiştir. Betimsel tarama yönteminin kullanıldığı araştırmada; veri toplama aracı olarak araştırmacı tarafindan geliştirilen "Kişisel Bilgi Formu" ve "Karakter Eğitimine İlişkin Görüş Ölçeği” kullanılmıştır. Araştırma verileri IBM SPSS 21.0 programı ile analiz edilmiştir. Verilerin analizinde bağımsız örneklemler için t-testi ve tek yönlü varyans analizi (ANOVA) kullanılmıştır. Araştırmanın sonucunda, pedagojik formasyon eğitimi sertifika programı öğrencilerinin karakter eğitimine ilişkin görüşlerinde cinsiyetlerine ve yaşlarına göre istatistiksel açıdan anlamlı bir farklılık görül- 
memiştir. Mezun olunan lisans programı değişkenine göre ise istatistiksel açıdan anlamlı farklılık saptanmıştır. Ayrıca bulgular ışığında çeşitli önerilerde bulunulmuștur.

Anahtar Kelimeler: Karakter eğitimi; Değer eğitimi; Pedagojik formasyon eğitimi.

\title{
Opinions of the Pedagogical Training Certificate Program Students About The Character Education
}

\begin{abstract}
The purpose of this study is to analyze pedagogical training certificate program students' opinions about the character education in terms of various variables. The study data are collected from 235 students enrolled in a pedagogical training certificate program at a state university in the 2013-2014 academic year. A Personal Information Form and a scale entitled "Opinions on Character Education Scale" developed by the researcher were used as data collection tools. The study is used with descriptive survey method. The study data were analyzed by IBM SPSS 21.0 program. The Independent Samples t-Test and One Way ANOVA were used for analyzing the data. As a result of the research, the views about character education by students of pedagogical formation certificate program did not show a statistically significant difference according to gender and age. However, that were diffirantiated significantly in regard to the graduated licience programs in statistical terms. Additionally, various suggestions have been made in the light of the data.
\end{abstract}

Keywords: Character education; Value education; Pedagogical training.

\section{Extended Summery}

\section{Purpose}

The researcher's purpose is to analyze the opinions of pedago- 
gical training certificate program students about the character education in terms of various variables (gender, age and graduated program). The descriptive scanning model was used in the survey.

\section{Method}

This research is carried out with descriptive scanning method. Descriptive scanning is used in a highly widespread manner in the field of education; because it helps researchers to summarize the characteristics (in terms of skills, preferences, behaviors, attitudes etc.) of individuals, groups or physical settings (e.g. schools).

The study group consists of 235 pedagogical training certificate program students participated in the study voluntarily being enrolled at a state university, graduated from the departments that are biology, chemistry, mathematics, history and Turkish language and literature, physics and music.

At the study, IBM SPSS 21.0 "Statistical Package for the Social Sciences" were used for analyzing data. The significance level was taken as $p \leq .05$ whole analyzes. IBM SPSS 21.0 and collected data have been tested with sufficient data analysis techniques. T-test one of the parametric analysis techniques and one way ANOVA were used for determining the total score that obtained from the scale to show varies for the purpose of this study according to the independent variable. As a result of analysis whether there is a significant difference, in this condition, the differences identifying the presence of which groups have been checked for homogeneity of variance. LSD one of the multiple 
comparison test was used to provide the homogeneous variance.

\section{Results}

The study data were collected by using "Personal Information Form" that located various variables gender, years, etc. and "Opinions on Character Education Scale" which developed by researcher. The study group of Opinions on Character Education Scale consists of 268 pedagogical training certificate program students being enrolled at a state university. 5-point likert-type form including 26 items were asked to participants to mark one of the options "Strongly Disagree", "Disagree", "Moderately Agree", "Agree" and "Completely Agree". The content validity of the scale have been consulted experts for testing and factor analysis was conducted in order to stick for construct validity. Items located in scale have been researched with Principal Component Analysis one of Exploratory Factor Analysis. Reliability of the scale was performed with the Cronbach's alpha, internal consistency coefficient and item-total correlations.

\section{Discussion and Conclusion}

At this study is purposed to analyze the opinions of pedagogical training certificate program students about character education in terms of various variables (gender, age and graduated program) the following conclusions were obtained:

According to gender, opinions of male participants on the character of education were found at higher level compared to female participants. However, the opinions of male and female participants 
about the character education significant difference was not found statistically. In other words, it is found that the gender variable does not have any impact on opinions of pedagogical training certificate program students in regard to the character education.

According to age variable, it is determined that the opinions of pedagogical training certificate program student regarding to character education did not differ as to the age levels. In other words, it is showed that the age variable does not have any impact on opinions of pedagogical training certificate program students about character education.

According to graduated licensing program variable, a significant difference is found statistically through the opinions of pedagogical training certificate program students about character education. It is found that pedagogical training certificate program students who graduated from biology and Turkish language and literature degree programs had more positive views than the students who graduated from mathematics and history degree programs and that created differentiation between graduate degree programs and pedagogical training certificate program on students' opinions in regard to the character education.

That recommendations can be made in line with the data of the study: Differences of opinion between the branches should be minimized by adding lessons related to character education to lesson plans in all branches of the university degree programs. Not seen any study about aiming to identify character education opinions revealed the 
necessity of studies in different ways on different samples. Therefore, it is though that similar studies, evaluated on broader and different samples contribute to the literature. This study is conducted pedagogical training certificate program students. In this regard, studies can be done for comparing the opinions on character education between different specialities students.

\section{Giriş}

Bir toplumun geleceği iyi yetişmiş ve karakter sahibi insanlara bağlıdır. Bununla birlikte karakter doğuştan gelmeyip, kişiye, eğitilme ve şuuraltının inşâsı yoluyla kazandırılır. Bu sebeple okullar, öğrencilerin doğru davranmayı bir hayat tarzı haline getirmelerine yardımcı olmak için onları gerekli değer ve becerilerle donatmayı da amaç edinmelidir. Okullar öğrencilere çağın getirdiği olumsuz durumlar karşısında iyi tercihler yapabilmek için stratejiler sunabilmelidirler (Uysal, 2008, s.22). İyi ve erdemli insan olmak, sağlam karakterli bireyler yetiştirmek ailenin, okulun ve toplumun en önemli amaçlarındandır. Çünkü sağlam karakterli olmak sadece bireylerin değil, toplumun da huzurlu ve mutlu olmasını sağlar (Karatay, 2011, s.1400).

Karakter kelimesinin literatürde birbirinden farklı pek çok tanımı yer almaktadır. Bunlardan bazıları şu şekildedir: Karakter; "Bir bireyin kendine özgü yapısı, onu başkalarından ayıran temel belirti ve bireyin davranış biçimlerini belirleyen ana özellik, öz yapı, ıra, seciye; bir kimsenin veya bir insan grubunun tutumu; duygulanma ve davranış biçimi; üstün, manevî özellik ve felsefî anlamda da bireyin kendi kendisine egemen olmasını, kendi kendisiyle uyum içinde bulunmasını, 
düşünüş ve hareketlerinde tutarlı, sağlam kalabilmesini sağlayan özellikler bütünü” (TDK, 2009, s.1077-1078), “Bir insanın, kişinin, davranış, alışkanlık, güç ve beceriler; değer ve düşünce tarzı türünden temel ögelerden meydana gelen özelliklerinin, onu başka insanlardan farklılaştıran bütünü" (Cevizci, 2003, s.222), "Elinden gelenin en iyisini yapma ve başkalarının iyiliğini arzulama gibi tutumları; eleştirel düşünme ve ahlâkî akıl yürütme gibi düşünsel kapasiteleri; dürüst ve sorumlu olma, âdil olmayan uygulamalar karşısında karşı durabilme gibi davranışları; başkalarıyla etkili bir biçimde iletişim kurma ve topluma katkı sağlama duyarlılı̆̆ını içermektedir" (Battistich, 2005, s.2).

"Karakter Eğitimi”" ise "istendik kişisel özelliklerin ya da niteliklerin gelişimini etkilemek için sarf edilen her türlü bilinçli ya da aleni çaba" olarak (Hoge, 2002, s.104) veya "öğrencilerin iyiyi bilmelerini, iyiyi arzulamalarını ve iyiyi yapmalarını sağlamak amacıyla yapılan kasitlı uygulamalar" şeklinde tanımlanabilir (Lickona, 1991, s.51). Bunlardan başka karakter eğitimini "en genel anlamıyla örtük veya açık program aracılığıyla, yetişen yeni nesle temel insanî değerleri kazandırma, değerlere karşı duyarlılık oluşturma ve onları davranışa dönüştürme konusunda yardımcı olma gayretinin ortak adı" (Ekşi, 2003, s.79) şeklinde ve çocukların ve gençlerin ilgili, dikkatli, sorumlu ve ilkeli olmalarına yardımcı olan toplum ve aile bireyleriyle sık sık birlikte olarak okul personeli tarafindan önceden plânlanmış yaklaşım şeklinde tanımlamak da mümkündür. $\mathrm{Bu}$ bağlamda karakter eğitimi; öğrencileri zihnen, kalben ve davranışlarıyla iyi alışkanlıklar edinmiş 
bireyler olarak yetiştirmede, ahlâkî sorumluluğu elde etmede ve özgüvenli vatandaş olmada öğrencilere yardım etmeyi amaçlamaktadır (Vess ve Halbur, 2003, s.1).

Karakter eğitimi yaygın olarak öğrencilerde temel etik değerleri anlama, onlara bağl1lık ve bu değerlere göre davranma eğilimini geliştirme süreci olarak tanımlanmaktadır. Karakter eğitimi taraftarları iyi karakterin, gizli müfredât yoluyla değil, açıkça öğretilmesi gerektiğini savunurlar (Gündoğdu, 2010, s.90). Meselâ Ryan (1986), bu konuda: "Uyarılar dikkatli kullanılmalı ve asla açıklama amacından uzaklaşmamalıdır. Yine de öğretmenlerin gençlerin en iyi dürtülerine hitap etmesi ve onları özgün bir yönde hareket etmeye zorlaması gereken zamanlar vardır." (akt; Gündoğdu, 2010, s.90) derken, karakter eğitiminin savunucularından William Bennett (1991) şu görüşü dile getirmektedir: "Eğer çocuklarımızın en çok imrendiğimiz karakter özelliklerine sahip olmasını istiyorsak, onlara bu özelliklerin neler olduğunu öğretmeliyiz.” (akt; Gündoğdu, 2010, s.90). Özetle, karakter eğitiminden geçmiş bireylerin zihnen, kalben ve davranışlarıyla iyi alışkanlıklar edinmiş olması hedeflenmektedir (Lickona, 1991, s.50).

Karakter eğitimini okullarda gerçekleştirecek olan elbette eğitimin temel taşı olan ögretmenlerdir. $\mathrm{Bu}$ nedenle karakter eğitiminde öğretmenlere önemli görevler düşmektedir.

Okullarda başarılı bir karakter eğitimi gerçekleştirmek amacıyla öğretmenlerin şu ilkelere dikkat etmeleri gerekmektedir (Ryan ve Bohlin, 1999, s.153-154): 
$\checkmark$ Ögretmenler iyi karakterleriyle model olmall ve kendi karakterlerini oluşturmalıdırlar.

$\checkmark$ Öğretmenler ögrencilerin ahlâkî hayat ve karakterini geliştirmeli ve bunu meslekî bir sorumluluk olarak kabul etmelidirler.

$\checkmark$ Öğretmenler ögrrencilerle hayatla ilgili olarak yani hayatta neyin doğru neyin yanlış olduğu konusunda konuşmalldirlar.

$\checkmark$ Öğretmenler ahlâkî konularda öğrencilerin düşünce ve görüşlerini yargılamadan kendilerini açıkça ifade etmelidirler.

$\checkmark$ Ögretmenler öğrencilerin empati kurmasını să̆lamalıdırlar. Öğrencilerin kendi dünyasından çıkarak başkalarının bakış açısından bakmalarına yardımcı olmalıdırlar.

Lickona (2001, s.4)'e göre etkili karakter eğitiminde 11 ilke yer almaktadır:

1. İyi karakterin temelini oluşturan etik değerleri geliştirir.

2. "Karakter" kavramını düşünce, duygu ve davranışı kapsayacak şekilde kapsamlı olarak tanımlar.

3. Kapsaml, kasitll, ileriye yönelik ve etkili bir karakter gelişimi yaklaşımını kullanır.

4. Insancıl bir okul topluluğu yaratır.

5. Öğrencilere ahlâkî eylem imkânları sunar.

6. Bütün ögrrenenlere saygl duyan, onların karakterini geliştiren ve başarılı olmalarına yardımcı olan anlamlı ve 
zorlayıcı bir akademik program içerir.

7. Öğrencilerin içsel güdülenmelerini arttırmaya çalışır.

8. Karakter ĕgitiminde sorumluluğu paylaşan ve ögrencilerin eğitimine rehberlik edecek aynı öz değerlere uymaya çalışan bir öğrenme ahlâk topluluğu olacak okul personeli taahhüt eder.

9. Karakter eğitimi inisiyatifinin ortak ahlâkî liderliğini ve uzun vadeli desteğini artırır.

10. Aileleri ve toplum üyelerini karakter oluşturma çabalarında ortaklar olarak işe koşar.

11. Okulun karakterini, okul personelinin karakter eğitimcileri olarak işlevini ve ögrencilerin ne ölçüde iyi karakter sergilediklerini değerlendirir.

Ulusal ve uluslararası alan-yazın incelendiğinde alan-yazında karakter eğitimi konusunda çeşitli çalışmalar (Aslan, 2011; Aytan, 2012; Avc1, 2011; Demirel, 2009; Gündoğdu, 2010; Katılmış, 2010; Uysal, 2008; Üstünyer, 2009; Yiğittir ve Bal, 2013; Yüksel, 2012) yer almasına rağmen karakter eğitimine ilişkin görüşleri belirlemeye yönelik herhangi bir araştırmaya rastlanmamıştır. Konunun önemi ve karakter eğitiminin öğrencilerin gelişimindeki faydaları göz önüne alındığında çeşitli branşlardan mezun olarak öğretmen olmak amacıyla pedagojik formasyon eğitimi almakta olan öğrencilerin karakter eğitimine ilişkin görüşlerinin belirlenmesinin literatüre katk1 sağlayacağ1 düşünülmektedir. $\mathrm{Bu}$ doğrultuda araştırmanın amacı, pedagojik formasyon eğitimi sertifika programı öğrencilerinin çeşitli değişkenler 
açısından (cinsiyet, yaş ve mezun olunan lisans programı) karakter eğitimine ilişkin görüşlerini incelemektir. $\mathrm{Bu}$ genel amaç doğrultusunda şu sorulara cevap aranmıştır:

1. Pedagojik formasyon eğitimi sertifika programı öğrencilerinin karakter eğitimine ilişkin görüşleri cinsiyet değişkenine göre farklılaşmakta mıdır?

2. Pedagojik formasyon eğitimi sertifika programı öğrencilerinin karakter eğitimine ilişkin görüşleri yaş değişkenine göre farklılaşmakta mıdır?

3. Pedagojik formasyon eğitimi sertifika programı öğrencilerinin karakter eğitimine ilişkin görüşleri mezun olunan lisans programı değişkenine göre farklılaşmakta mıdır?

\section{Yöntem}

\section{Araştırma Modeli}

$\mathrm{Bu}$ araştırma betimsel tarama (survey) yöntemi kullanılarak gerçekleştirilmiştir. Tarama yöntemi genellikle eğitim araştırmalarında seçilen grubun belirli bir konu hakkında tutum, inanç ve görüşlerini öğrenmek amacıyla kullanılmaktadır (McMillan ve Schumacher, 2006). Bu nedenle bu çalışmada da temel araştırma deseni olarak betimsel tarama (survey) yöntemi kullanılmıştır.

\section{Çalışma Grubu}

Araştırmanın çalışma grubunu; gönüllülük esasına göre bir devlet üniversitesinin pedagojik formasyon eğitimi sertifika programında kayıtlı biyoloji, kimya, matematik, tarih, Türk dili ve edebiyatı, fizik ve 
müzik lisans programlarından mezun toplam 235 öğrenci oluşturmaktadir.

\section{Verilerin Toplanması}

Araştırma verileri, katılımcıların cinsiyet, yaş ve mezun olunan lisans programı değişkenlerinin yer aldığ 1 araştırmacı tarafından oluşturulan "Kişisel Bilgi Formu" ve araştırmacı tarafından geliştirilmiş olan “Karakter Eğitimine İlişkin Görüş Ölçeği”” ile elde edilmiştir.

“Karakter Eğitimine İlişkin Görüş Ölçeği”nin çalışma grubunu bir devlet üniversitesinin pedagojik formasyon eğitimi sertifika programına kayıtlı 268 öğrenci oluşturmuştur. 5'li likert tipi formunda 26 maddeden oluşan ölçekte katılımcıların her maddenin karşısında bulunan "Kesinlikle Katılmıyorum", "Katılmıyorum”, "Orta Derecede Kat1lıyorum", "Katıl1yorum” ve "Tamamen Katılıyorum” seçeneklerinden birini işaretlemeleri istenmiştir. Ölçeğin kapsam geçerliğini test etmek için uzman görüşlerine başvurulmuş, yapı geçerliğini saptamak amacıyla da faktör analizi yapılmıştır. Ölçekte yer alan maddeler “Açımlayıcı Faktör Analizi” tekniklerinden "Temel Bileşenler Analizi” ile incelenmiştir. Ölçeğin güvenirlik çalışmaları ise "Cronbach Alpha" iç tutarlılık katsayısı ve madde toplam korelasyonları ile gerçekleştirilmiştir. Ölçme aracının çalışma grubuna uygulanması sonucu elde edilen verilerin çalışma grubuna uygunluğu .000 düzeyinde "Kaiser-Meyer-Olkin" $(\mathrm{KMO})=.859$ "Bartlett Testi” sonucu $\mathbf{x}^{2}=1324.217$ olarak bulunmuştur.

“Karakter Eğitimine İlişkin Görüş Ölçeği”’ ilgili literatür taraması 
ve uzman görüşleri sonrasında 26 maddelik taslak ölçek olarak hazırlanmıştır. Hazırlanan taslağın pilot uygulaması, bir devlet üniversitesinin pedagojik formasyon eğitimi sertifika programında öğrenim görmekte olan 235 öğrenci ile gerçekleştirilmiştir. Ölçek geliştirme süreci sonunda toplam varyansın 48.207 'sını açıklayan ve 8.014 özdeğerine sahip tek faktörlü yapıda 21 maddelik bir ölçek elde edilmiştir. Ölçekteki maddelerin madde toplam korelasyon değerleri 305 ile .480 ve madde faktör yükleri .311 ile .693 aralığında yer almaktadır. Maddelerinin iç tutarlılığına yönelik Cronbach Alfa katsayısı ise .856 değerinde bulunmuştur. Analizler sonucu elde edilen bu değerler, ölçeğin kabul edilebilir standartlarda geçerli ve güvenilir olduğunu göstermiştir. Diğer bir ifadeyle elde edilen bulgular sonucu ölçeğin karakter eğitimine ilişkin görüşleri ölçebilecek yeterlikte olduğu görülmüştür.

\section{Verilerin Analizi}

Araştırmada uygulanan ölçekten elde edilen verilerinin analizinde, IBM SPSS 21.0 "Statistical Package for the Social Sciences" paket programı kullanılmış, yapılan bütün analizlerde anlamlılık düzeyi $p \leq .05$ olarak alınmıştır. Bu program ile eldeki veriler araştırma amacına uygun analiz teknikleriyle test edilmiştir. Araştırmanın amaçları doğrultusunda ölçekten alınan toplam puanların bağımsız değişkenlere göre farklılık gösterip göstermediğini belirlemek amacıyla parametrik analiz tekniklerinden bağımsız örneklemler için t-testi ve tek yönlü varyans analizi (ANOVA) uygulanmıştır. Analizler sonucunda anlamlı farklılığın ortaya çıkması durumunda, farklılı̆̆ın hangi gruplar arasında 
olduğunu belirlemek için varyansların homojenliği kontrol edilmiştir. Varyansların homojen olması durumunda çoklu karşılaştırma testlerinden LSD testi kullanılmıştır.

\section{Bulgular}

\section{Cinsiyet Değişkenine İlişkin Bulgular}

Pedagojik formasyon eğitimi sertifika programı öğrencilerinin cinsiyetleri ile karakter eğitimine ilişkin görüşleri arasında anlamlı bir farkın olup olmadığı bağımsız örneklemler için t-testi ile analiz edilmiş ve analiz sonuçları Tablo 1'de gösterilmiştir.

Tablo 1. Pedagojik Formasyon Eğitimi Sertifika Programı Öğrencilerinin Karakter Eğitimine İlişkin Görüşlerinin Cinsiyetlerine Göre t-Testi Sonuçları

\begin{tabular}{ccccccc}
\hline Cinsiyet & $\mathbf{N}$ & $\overline{\mathrm{X}}$ & Ss & sd & $\mathbf{t}$ & $\boldsymbol{p}$ \\
\hline Kadın & 147 & 79.65 & 12.58 & \multirow{2}{*}{233} & \multirow{2}{*}{1.392} & $.165^{*}$ \\
Erkek & 88 & 81.84 & 9.93 & & & \\
\hline
\end{tabular}

$* p>.05$

Tablo 1 incelendiğinde, erkek katılımcıların karakter eğitimine ilişkin görüşlerinin ( $\bar{X}=81.84)$, kadın katılımcılara $(\bar{X}=79.65)$ göre daha yüksek seviyede olduğu görülmektedir. Ancak, istatistiksel olarak erkek ve kadın katılımcıların karakter eğitimine ilişkin görüşleri arasında istatistiksel açıdan anlamlı bir fark bulunamamıştır $\left[\mathrm{t}_{(233)}=1.392\right.$; $p>.05]$. Bu bulgu, cinsiyet değişkeninin pedagojik formasyon eğitimi sertifika programı öğrencilerinin karakter eğitimine ilişkin görüşleri üzerinde herhangi bir etkiye sahip olmadığı şeklinde yorumlanabilir. 


\section{Yaş Değişkenine İlişkin Bulgular}

Pedagojik formasyon eğitimi sertifika programı öğrencilerinin yaşları ile karakter eğitimine ilişkin görüş ortalamaları arasında anlamlı bir farkın olup olmadığı tek yönlü varyans analizi ile analiz edilmiş ve analiz sonuçları Tablo 2'de gösterilmiştir.

Tablo 2. Pedagojik Formasyon Eğitimi Sertifika Programı Öğrencilerinin Karakter Eğitimine İlişkin Görüş Toplam Puanlarının Yaş Değişkenine Göre Tek Yönlü Varyans Analizi (ANOVA) Sonuçları

\begin{tabular}{|c|c|c|c|c|c|c|}
\hline & Değişken & & & $\mathbf{N}$ & $\overline{\mathrm{x}}$ & Ss \\
\hline \multirow{10}{*}{ Yaş } & 18-22 Yaş & & & 34 & 82.52 & 7.43 \\
\hline & 23-27 Yaş & & & 137 & 79.48 & 12.13 \\
\hline & 28-32 Yaş & & & 47 & 82.17 & 11.88 \\
\hline & 33-37 Yaş & & & 12 & 82.66 & 8.51 \\
\hline & 38 Yaş ve Üzer & & & 5 & 72.40 & 22.38 \\
\hline & Toplam & & & 235 & 80.47 & 11.68 \\
\hline & $\begin{array}{l}\text { Varyansın } \\
\text { Kaynağı }\end{array}$ & $\mathbf{K T}$ & Sd & KO & $\mathbf{F}$ & $p$ \\
\hline & Gruplar Aras1 & 797.390 & 4 & 199.348 & 1.471 & \\
\hline & Gruplar İçi & 31163.18 & 230 & 135.492 & & $.212^{*}$ \\
\hline & Toplam & 31960.57 & 234 & & & \\
\hline
\end{tabular}

Tablo 2 incelendiğinde, pedagojik formasyon eğitimi sertifika programı öğrencilerinin karakter eğitimine ilişkin görüşlerinin yaş düzeylerine göre farklılaşmadığ görülmüştür $\left[\mathrm{F}_{(4-230)}=1.471, p>.05\right]$. $\mathrm{Bu}$ bulgu, yaş değişkeninin pedagojik formasyon eğitimi sertifika programı öğrencilerinin karakter eğitimine ilişkin görüşleri üzerinde herhangi bir etkiye sahip olmadığı şeklinde yorumlanabilir. 


\section{Mezun Olunan Lisans Programı Değişkenine İlişkin Bulgular}

Pedagojik formasyon eğitimi sertifika programı öğrencilerinin mezun oldukları lisans programı ile karakter eğitimine ilişkin görüş ortalamaları arasında anlamlı bir farkın olup olmadığı tek yönlü varyans analizi ile analiz edilmiş ve analiz sonuçları Tablo 3 'te gösterilmiştir.

Tablo 3. Pedagojik Formasyon Eğitimi Sertifika Programı Öğrencilerinin Karakter Eğitimine İlişkin Görüş Toplam Puanlarının Mezun Olunan Lisans Programı Değişkenine Göre Tek Yönlü Varyans Analizi (ANOVA) Sonuçları

\begin{tabular}{|c|c|c|c|c|c|c|c|}
\hline \multicolumn{3}{|c|}{ Değişken } & & $\mathbf{N}$ & \multicolumn{2}{|c|}{$\overline{\mathrm{X}}$} & Ss \\
\hline \multirow{12}{*}{ 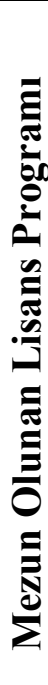 } & \multicolumn{2}{|l|}{ (1) Biyoloji } & & 19 & \multicolumn{2}{|c|}{85.42} & 9.23 \\
\hline & \multicolumn{2}{|l|}{ (2) Kimya } & & 15 & \multicolumn{2}{|c|}{82.13} & 8.81 \\
\hline & \multicolumn{2}{|l|}{ (3) Matematik } & & 42 & \multicolumn{2}{|c|}{76.47} & 13.15 \\
\hline & \multicolumn{2}{|l|}{ (4) Tarih } & & 47 & \multicolumn{2}{|c|}{76.34} & 15.93 \\
\hline & \multicolumn{2}{|c|}{ (5) Türk Dili ve Edebiyatı } & & 105 & \multicolumn{2}{|c|}{82.36} & 8.71 \\
\hline & \multicolumn{2}{|c|}{ (6) Fizik } & & 3 & \multicolumn{2}{|c|}{86.66} & 4.04 \\
\hline & \multicolumn{2}{|l|}{ (7) Müzik } & & 4 & \multicolumn{2}{|c|}{87.00} & 1.41 \\
\hline & \multicolumn{2}{|l|}{ Toplam } & & 235 & \multicolumn{2}{|c|}{80.47} & 11.68 \\
\hline & $\begin{array}{l}\text { Varyansın } \\
\text { Kaynăgı }\end{array}$ & KT & sd & KO & $\mathbf{F}$ & $p$ & $\begin{array}{l}\text { Fark } \\
\text { (LSD) }\end{array}$ \\
\hline & Gruplar Aras1 & 2640.26 & 6 & 440.04 & 3.422 & $.003 *$ & $1-3$ \\
\hline & Gruplar İçi & 29320.30 & 228 & 128.59 & & & $1-4$ \\
\hline & Toplam & 31960.57 & 234 & & & & $\begin{array}{l}3-5 \\
4-5\end{array}$ \\
\hline
\end{tabular}

Tablo 3 incelendiğinde, pedagojik formasyon eğitimi sertifika programı öğrencilerinin mezun oldukları lisans programı ile karakter eğitimine ilişkin görüşleri arasında istatistiksel açıdan anlamlı bir fark olduğu görülmüştür $\left[\mathrm{F}_{(6-228)}=3.422, p<.05\right]$. Anlamlı farklılıkların 
hangi lisans programları arasında olduğunu belirlemek amacıyla LSD çoklu karşılaştırma testi yapılmıştır. LSD testi sonuçlarına göre, biyoloji ( $\bar{X}=85.42)$ ve Türk dili ve edebiyatı $(\bar{X}=82.36)$ lisans programından mezun olan pedagojik formasyon eğitimi sertifika programı öğrencilerinin, matematik ( $\bar{X}=76.47)$ ve tarih $(\bar{X}=76.34)$ lisans programlarından mezun olan pedagojik formasyon eğitimi sertifika programı öğrencilerine göre karakter eğitimine ilişkin görüşlerinin daha olumlu olduğu görülmüştür. Araştırmanın bu bulgusu pedagojik formasyon eğitimi sertifika programı öğrencilerinin karakter eğitimine ilişkin görüşleri üzerinde mezun oldukları lisans programının farklılaşma yarattığı şeklinde yorumlanabilir. Bu durum pedagojik formasyon eğitimi sertifika programında öğrenim gören öğrencilerin birbiriyle ilgili olmayan çeşitli branşlardan mezun olmalarından, dolayısıyla birbirinden farklı ve çok çeşitli dersler almalarından kaynaklanıyor olabilir.

\section{Tartışma, Sonuçlar ve Öneriler}

Pedagojik formasyon eğitimi sertifika programı öğrencilerinin farklı değişkenler açısından (cinsiyet, yaş ve mezun olunan lisans programı) karakter eğitimine ilişkin görüşlerini incelemeyi amaçlayan bu araştırmada şu sonuçlar elde edilmiştir:

Cinsiyet değişkenine göre, erkek katılımcıların karakter eğitimine ilişkin görüşlerinin, kadın katılımcılara göre daha yüksek seviyede olduğu saptanmıştır. Fakat istatistiksel olarak erkek ve kadın katılımcıların karakter eğitimine ilişkin görüşleri arasında istatistiksel açıdan anlamlı bir fark bulunamamıștır. Diğer bir ifadeyle, cinsiyet 
değişkeninin pedagojik formasyon eğitimi sertifika programı öğrencilerinin karakter eğitimine ilişkin görüşleri üzerinde herhangi bir etkiye sahip olmadığg söylenebilir. Katılımcıların karakter eğitimine ilişsin görüşlerinin cinsiyetlerine göre benzerlik göstermiş olması, mezun oldukları lisans programlarında karakter eğitimine yönelik herhangi bir dersin bulunmamasından kaynaklanıyor olabilir.

Yaş değişkenine göre, pedagojik formasyon eğitimi sertifika programı öğrencilerinin karakter eğitimine ilişkin görüşlerinin yaş seviyelerine göre farklılaşmadığı saptanmıştır. Başka bir ifadeyle bu bulgu, yaş değişkeninin pedagojik formasyon eğitimi sertifika programı öğrencilerinin karakter eğitimine ilişkin görüşleri üzerinde herhangi bir etkiye sahip olmadığ şeklinde yorumlanabilir. Katılımcıların karakter eğitimine ilişkin görüşlerinin yaşlarına göre farklılık göstermemiş olması, katılımcıların hepsinin üniversite mezunu olmasından, dolayısıyla yaşları itibariyle belirli bir olgunluğa erişmiş olmalarından kaynaklanıyor olabilir.

Mezun olunan lisans programı değişkenine göre, pedagojik formasyon eğitimi sertifika programı öğrencilerinin mezun oldukları lisans programı ile karakter eğitimine ilişkin görüşleri arasında istatistiksel açıdan anlamlı bir fark olduğu saptanmıştır. Bu tespit ışığında, biyoloji ve Türk dili ve edebiyatı lisans programından mezun olan pedagojik formasyon eğitimi sertifika programı öğrencilerinin, matematik ve tarih lisans programlarından mezun olan pedagojik formasyon eğitimi sertifika programı öğrencilerine göre karakter eğitimine ilişkin görüşlerinin daha olumlu olduğu söylenebilir ve pedagojik formasyon 
eğitimi sertifika programı öğrencilerinin karakter eğitimine ilişkin görüşleri üzerinde mezun oldukları lisans programının farklılaşma yarattığ 1 şeklinde yorumlanabilir. Araştırmanın bu sonucu pedagojik formasyon eğitimi sertifika programında öğrenim gören öğrencilerin birbiriyle ilgili olmayan çeşitli branşlardan mezun olmalarından, dolayısıyla birbirinden farklı ve çok çeşitli dersler almalarından kaynaklanıyor olabilir.

Araştırmadan elde edilen bulgular doğrultusunda şu önerilerde bulunulabilir:

Üniversitelerin lisans programlarındaki bütün branşların ders plânlarına karakter eğitimine ilişkin dersler eklenerek, branşlar arasındaki görüş farklılıkları en aza indirilmelidir.

Konu hakkında şu genel önerilerde bulunulabilir:

İlgili literatürde karakter eğitimine ilişkin görüşleri belirlemeyi amaçlayan herhangi bir çalışmaya rastlanmamış olunması farklı örneklemler üzerinde farklı yöntemlerle araştırmaların gerçekleştirilmesi gerekliliğini ortaya çıkarmaktadır. Bu sebeple gerçekleştirilecek benzer çalışmaların, daha geniş ve farklı çalışma grupları üzerinde değerlendirilmesinin alan-yazına katkı sağlayacağı düşünülmektedir. Bu çalışma pedagojik formasyon eğitimi sertifika programı öğrencilerine yönelik olarak gerçekleştirilmiştir. Bu doğrultuda farklı branşlardaki öğrencilere yönelik çalışmalar gerçekleştirilerek öğrencilerin karakter eğitimine ilişkin görüşleri arasında karşılaştırmalar yapılabilir. 


\section{Kaynakça}

Aslan, M. (2011). Illköğretimde karakter ĕgitimi ve öğrencilere kazandırılması gereken değerler. Yayınlanmamış yüksek lisans tezi, Eskişehir Osmangazi Üniversitesi Eğitim Bilimleri Enstitüsü.

Avc1, E. (2011). Illköğretim sosyal bilgiler öğretmenlerinin karakter eğitimine dair öz-yeterliklerinin incelenmesi. Yayınlanmamış doktora tezi, Gazi Üniversitesi Eğitim Bilimleri Enstitüsü.

Aytan, N. (2012). İlköğretim ikinci kademe Türkçe ders kitaplarındaki masal ve hikâyelerin karakter eğitimi açısından incelenmesi. Yayınlanmamış yüksek lisans tezi, Çanakkale Onsekiz Mart Üniversitesi Eğitim Bilimleri Enstitüsü.

Battistich, V. (2005). Character education, prevention and positive youth development, Washington DC: Character Education Partnership.

Cevizci, A. (2003). Felsefe terimleri sözlüğü. İstanbul: Paradigma Yayınları.

Demirel, M. (2009). Sınıf öğretmenlerinin ve okul yöneticilerinin karakter eğitimine ilişkin öz-yeterlik inançları. Hacettepe Üniversitesi Ĕ̆itim Fakültesi Dergisi, 37, 36-49.

Ekşi, H. (2003). Temel insanî değerlerin kazandırılmasında bir yaklaŞım: Karakter eğitimi programları. Dĕ̌gerler Ĕ̆itimi Dergisi, 1(1), 79-96.

Gündoğdu, F. B. (2010). Ortaöğretim kurumlarında karakter ĕgitimi sorunu (Kayseri ili örneği). Yayınlanmamış yüksek lisans tezi, Erciyes Üniversitesi Sosyal Bilimler Enstitüsü.

Hoge, J. D. (2002). Character education, citizinship education and the social studies. The Social Studies. 93(3), 103-108. 
Karatay, H. (2011). Karakter eğitiminde edebi eserlerin kullanımı. Turkish Studies, 6(1), 1398-1412.

Katılmış, A. (2010). Sosyal bilgiler derslerindeki bazı dĕgerlerin kazandırılmasına yönelik bir karakter eğitimi programının geliştirilmesi. Yayınlanmamış doktora tezi, Marmara Üniversitesi Eğitim Bilimleri Enstitüsü.

Lickona, T. (6 Ekim 2001). What is effective character education? By Thomas Lickona. The stony brook school symposium on character. 20 Mart 2015,

http://www.mtsm.org/pdf/What\%20is\%20Effective\%20Charact er\%20Education.pdf.

Lickona, T. (1991). Educating for character: How our schools can teach respect and responsibility. New York: Bantam Books.

McMillan, H. J. ve Schumacher, S. (2006). Research in education evidence-based inquiry. Boston: Allyn and Bacon Inc.

Ryan, K. ve Bohlin, K. E. (1999). Building character in schools. San Francisco: Jossey-Bass Publishers.

TDK. (2009). Türkçe sözlük, Ankara: Türk Dil Kurumu Yayınları.

Uysal, F. (2008). Karakter eğitimi programlarının değerlendirilmesi. Yayınlanmamış yüksek lisans tezi, Yeditepe Üniversitesi Sosyal Bilimler Enstitüsü.

Üstünyer, F. (2009). Karakter eğitimi ile ilgili eğitimcilerin görüşleri üzerine nitel bir araştırma. Yayınlanmamış yüksek lisans tezi, Yeditepe Üniversitesi Sosyal Bilimler Enstitüsü.

Vess, K. A. ve Halbur, D. A. (2003). Character education: What counselor educators need to know. ERIC Clearinghouse on Counse- 
ling and Student Services Greensboro NC. Retrieved 14 Şubat 2014, http://www.ericdigests.org/2003-5/character.htm.

Yiğittir, S. ve Bal, M. S. (2013). Sosyal bilgiler dersinde karakter eğitimi. KSÜ Sosyal Bilimler Dergisi, 10(2), 239-260.

Yüksel, G. (2012). Illköğretim öğretmenlerinin karakter ĕgitimi yetkinlik inançları ile ahlâkî olgunluk düzeyleri arasındaki ilişki. Yayınlanmamış yüksek lisans tezi, Eskişehir Osmangazi Üniversitesi Eğitim Bilimleri Enstitüsü. 